\title{
Between Reflection on Practice and the Practice of Reflection: A Case Study from Aviation
}

\begin{abstract}
Reflection on practice continues to gain increasing support, if not a requirement, within vocational and professional fields. As a method of instruction, it can be used to develop increased awareness of individual performance and support lifelong learning. However, whereas research generally focuses on how individuals become proficient practitioners through reflection, it is less concerned, if at all, with how individuals learn to become proficient as practitioners of reflection. This paper turns to an example from aviation to describe a modification of practice that makes reflection an integral part of practice. In our partner airline, all pilots not only engage in reflection on practice for improving practice but also in activities that improve the practice of their reflections. Training pilots to assess video recorded sessions of other pilots-via benchmark training-is viewed as an important step in improving pilots ability to review their own performance during their bi-annual performance assessment.
\end{abstract}

Keywords: reflective practice; performance assessment; technical skills; nontechnical skills; aviation; benchmarking

Pilot 1: Fantastic. Great. That's our bread and butter, that's what we do. People like, people enjoy watching other crews doing stuff we do everyday.

Pilot 2: Because you can make, you can relate it to yourself straight away, can't you? You can always come up with a scenario that.

Pilot 1: Yeah, you will always find something interesting in some audiovisual.

The two pilots are commenting on the experience of having assessed colleagues, over a period of three hours, who appear in videotapes recorded while the latter are flying various scenarios in a flight simulator. During the task, organized by their human resources department, the two pilots used the same assessment form (instrument) that is used for evaluating their own performance during the two-day biannual examinations that each pilot has to undergo. Pilot 1 is also a training captain, which means, he trains new pilots in the company, and in doing so, uses the same assessment form to evaluate trainees. Importantly, both pilots not only enjoy this part of their crew resource management training but, pointed out here by Pilot 2, analyzing the performance of peers allows them to relate what they observe to themselves. In relating observations to themselves, they reflect on what they do while actually flying an aircraft. One further step in the integration of assessment and reflection on practice will come about when Pilot 1 moves to the next rank: flight examiner. In this case, he will participate in the two annual evaluations of pilots as an assessor of other company pilots, including the evaluation of other flight examiners.

This episode shows how reflective practice in the two pilots' airline has gone one step further than what we can observe in most situations where it has 
already been used. The pilots are not merely reflecting on practice-either as part of their crew resource management training, leisure activity, or in the context of research on reflective practice-but reflection on practice is made to occur throughout their normal work activities and is made part of their career progress. In this airline, new pilots (first officers) are trained to use assessment forms, current pilots use the form to analyze videotaped scenarios, and flight examiners use the form to assess all pilots (including flight examiners). The aim is to make all pilots doubly competent: as pilots and as evaluators of pilots; and all pilots, through the reflection on the practices of others, reflecting on their own practices. That is, all pilots both use and are subjected to the same assessment form. Becoming competent in assessment-and therefore to reflecting on the practice of flying an aircraft more generally-is integral to the career process.

The purpose of this paper is to provide an ethnographic description of how the airline got to that point and what it does to engage pilots in reflective practice as part of their career trajectories. We contextualize our study in a brief review of current models of reflective practice and end with some comments on the transportability of the model to other professions. In presenting this approach to professional development, this paper is designed to contribute as an extension to current models of reflective practice. Essentially, in the model we present, reflective practice is designed not only to improve the practice of flying, but also the practice of reflection, which, in this particular case, exists in the form of performance assessment training.

\section{Reflection: models of reflective practice}

Reflective practice can be interpreted as being the practitioner's ability to access, make sense of and learn through work experience to achieve more desirable, effective and satisfying work. (Johns, 1995, p. 23-24)

Discussion, critique, and work in the area of reflective practice-a means of reducing the professional-training and professional-practice gap-have been based heavily on the work of Donald Schön $(1983,1987)$. From its original formulation, reflective practice was presented as a means for practitioners to develop their practice-relevant knowledge and skills that are not or cannot be taught within a traditional training program. With this in mind, one might ask, 'Are some methods of reflective practice more appropriate then others for bridging this classroom-practice gap?'

There currently are different methods employed for engaging practitioners in reflective practice. One of the most common means used in areas such as health, management, human resource development, sport, and university education is the reflective journal (O'Connell \& Dyment, 2011). The reflective journalsometimes referred to as skills portfolio-requires individuals to write, in many cases in an informal way, a diary where they report stories of everyday events in the workplace. In some professions, multiple journals are kept, which include a professional portfolio and research diary (Howarth, 2005). The reflective journal remains a stalwart method for reflective practice with advantages being that it makes for student-centered learning because it enables them to be critically 
reflective and creative (0'Connell \& Dyment, 2011). However, its relevance has been questioned, some scholars arguing that students tend to interrogate their practice only superficially (Betts, 2004) or that reflections are mechanical rather then addressing or analyzing deeper issues within their own practice (Holden \& Griggs, 2011). Further criticism is aimed at the limited instruction sometimes given to students on how to write a journal; students tend to write for the instructors rather then for themselves; and, journaling does not meet the needs of all students (O'Connell \& Dyment, 2011).

Other methods of reflective practice include role-playing tasks. Within clinical supervision of nurses, role-play can aid in developing a nurse's abilities to deal with new situations and can 'facilitate the exploration of emotions, thoughts and predictions that were pertinent to a situation' (Todd, 2005, p. 43). Though some negatives include creating discomfort for those involved and the fear that these role-play activities can unveil weaknesses both within the student and the mentor. Additional methods of reflective practice include the use of critical incident analysis. Whereas it originated in aviation nearly half a century ago, critical incident analysis has been taken up in many other professions. It requires individuals or groups to review in depth a critical event from their practice. General formats of critical event analysis may include: an account of the incident; an initial overview of the responses to the incident; issues that where identified and problems brought to light; what was learned; and a review of the outcomes (Lister \& Crisp, 2007). For some students, critical incident analysis is an effective means of reflection-on-action (Schön, 1983) and for planning future action (Holden \& Griggs, 2011). This planning for future action is commonly referred to in recent literate as reflection-for-action (Thompson \& Pascal, 2012). Here, the preposition for emphasizes the fact that reflection is designed not only to generate understanding of practice but also to produce new action possibilities (Roth, 2010).

Using audio and video recordings as a resource for professional development has become quite common for the teaching of technical knowledge and skills. The use of this type of media-e.g. film segments from TV programs, mock-up scenarios filmed by the teacher, or recordings of a student's actual performance-is less frequent for professional development and reflective practice (Hulsman, Harmsen, \& Fabriek, 2009; Todd, 2005). For instance, in a study with dentistry students, researchers recognized students had limited professional experience to reflect on (Brett-MacLean, Cave, Yiu, Kelner, \& Ross, 2010). To facilitate greater connectedness to their profession, short film clips were used to engage in student reflection. However, the clips lacked relevance to dentistry, which created problems for transferring what they learned to their own field. Later use of a longer more relevant film-e.g., Ghost Town-enabled students to improve the reflection practices. Thus, 'the movie offered lots of opportunities to talk about becoming a dental professional' (p. 508). In another study from medical education, pre-recorded videos of clinical consultations were used for student training (Koole et al., 2012). In this study, students viewed the videos and where asked to interpret what happened and subsequent actions they would recommend. Rather then assessing the performance of actors in the video, the purpose was for students to reflect on their own professional interpretation of the video and intended actions at the end of the training 
session. Positive reflection results where identified when students conducted a survey instrument to record their reflection.

Video also has been used to record students' own practices. It has been shown that students' self-assessment of recordings of their own performance can improve practice (Ward et al., 2003), with further improvements occurring when self-assessment is conducted in the presence of peers and senior staff (Lane \& Gottlieb, 2004; Scherer, Chang, Meredith, \& Battistella, 2003). Other approaches to review video-recordings include professional and world-class amateur sports, where, as we know from personal experience, video has been used for more than 50 years to engage athletes in reflective practice to promote improved performance (e.g., Rowperfect, 2014). For example, in elite netball, the use of video replay of previous games and training sessions assist team members to develop improved understanding of performance (Richards, Collins, \& Mascarenhas, 2012).

In all of these approaches outlined, individuals are asked to review their own, or other individuals' performances using a variety of techniques. These approaches, however, have not gone without challenge. An issue that continues to arise relating to reflection, or self-assessment, is the intrinsic difficulty individuals have conducting self-assessment (Dunning, Johnson, Ehrlinger, \& Kruger, 2003; Dunning \& Suls, 2004; Gurung, Daniel, \& Landrum, 2012; Sitzmann, Ely, Brown, \& Bauer, 2010). There are also suggestions that many of the studies on self-assessment are related to assessing one's own performance immediately after an assessment, rather then the efficacy of self-assessment that occurs 'sometimes without our conscious awareness' or its effect on long term practice (Mann, 2010, p. 312). Moreover, the assumption that learning in the classroom is simply transferable into practice by means of a one-way pipe, where the learner is an empty vessel waiting to be filled has been challenged over many years (Schön, 1983, 1987). Even today, it is argued, that within occupational settings 'there is no distinction between engaging in practice and learning' (Billett, 2010, p. 2). Simply put, how individuals actually engage with the knowledge they are learning, that is, how they generate new knowledge to be used in real practice settings is not well understood (Eraut, 2010). How individuals learn to work by themselves, or in teams, by enacting classroombased instruction into the filed, or, use that instruction to assist them is still underdeveloped. There remain unanswered questions about the classroompractice gap in professions such as aviation (Munro \& Mavin, 2012), teaching and higher education (Dochy, Segers, \& Sluijsmans, 1999; Kelly, Luke, \& Green, 2008), the medical industry (Clouder, 2000), or the maritime industry (Emad \& Roth, 2008). Some scholars therefore have argued for a more rigorous approach to developing theory within reflective practice (Thompson \& Pascal, 2012). Accordingly, analyzing current approaches to reflective practice may assist in the development of such theory.

In this paper the authors describe how one airline company made reflective practice an integral element of its operations. The three-stage process of implementation involved (a) designing clear performance criteria, (b) broadening assessment training to all personal-in this paper all pilotsincluding captains and first officers and not just senior flight examiner, and (c) making assessment training authentic. 


\section{Teaching pilots not only to-reflect, but, how-to-reflect: a three-stage process}

In this section, we describe how together with one airline, we developed a model of reflective practice where the assessment of performance became an integral aspect of work (practice).

\section{Pre-history of introducing performance assessment into an airline}

In 2011, our partner airline asked for assistance in examining new approaches to training and assessment. After a lengthy review, two central issues were identified: First, the company's regular, classroom-based crew resource management training did not transfer to the cockpit. For most pilotsflight examiners (senior captains delegated to assess other pilots performance), captains (pilot in command of aircraft) and first officers (second-in-command)there was a theory-practice based issue: they felt that there was a lot of theory in the classroom that somehow did not apply to their daily work. Second, some pilots-in some cases over many years-returned to their bi-annual assessment with little if any improvement apparent. The airline wanted to improve the existing, annual classroom-based instruction to better align with the pilots' twoday bi-annual examination and performance assessment.

\section{Stage 1: The development of clear criteria and appropriate training resources}

A first step toward greater relevance of training and on-the-job performance required finding a model for assessing performance. The model needed to be accessible to pilots so that they could understand performance requirements; to facilitate self-assess for the purpose of improving their practice. One of the fundamental reasons why inaccuracy in self-assessment occurs is the ill-defined nature of competence' (Dunning \& Suls, 2004, p. 74). For example, assessing whether a correct procedure was used to complete a simple task can be more easily defined than 'sound' performance in 'the handling of an emergency'. Traditionally, assessment of pilot performance focused on technical knowledge and technical proficiency. Technical knowledge included understanding aircraft systems, rules of the air, and airline standard operating procedures; technical proficiency refers to a pilot's ability to fly the aircraft within strict parameters set by an airline. Whereas both remain fundamental (Johnston, Rushby, \& Maclean, 2000), other performance aspects have now been identified as equally important, including situational awareness, decision-making, teamwork, management, and communication (Helmreich \& Foushee, 1993). In fact, these latter performance aspects, currently considered to constitute non-technical skills, are said to be the source of more than half the worldwide accident rate (Flin, O'Connor, \& Crichton, 2009).

Assessment of technical knowledge and technical proficiency show that the criteria used are perceived as being more objective (Mavin \& Murray, 2010). For example, technical proficiency is easily assessable: Did the pilot fly the plane within 100 feet of the specified altitude? Did the pilot keep the airspeed within 5 knots of the required speed? On the other hand, the non-technical aspects of 
flying-e.g., quality of communication or management of crew-are less easily measured. Identifying what constitutes sufficient decision-making or poor communication performance generally was left to the professional sense of individual examiner. There is, however, considerable variation in performance assessment of pilots even when assessor work in pairs (Mavin, Roth, \& Dekker, 2013); and, as additional research showed, assessors actually provide very good reasons for varying in their assessments (Roth \& Mavin, 2013).

In the light of moving towards a clearer picture of how our airline viewed performance, it adopted a new, holistic model of pilot performance. The model for assessing a pilots' performance (MAPP) incorporated both technical and nontechnical skills into a single unifying model. As shown in Figure 1, the model does not separate technical and non-technical performance aspects, as this has occurred in the past but rather treats performance components as interrelated and hierarchical (Mavin \& Dall'Alba, 2010). Although all components are integral to good performance, situational awareness takes an integrative role. The enabling skills - aviation knowledge, management, and communication-are seen to be subordinate to essential skills. The MAPP is a heuristic for examining piloting performance and it enables all pilots to better understand how senior examiners look at their performance.

\section{««««« Insert Figure 1 about here »»»»»»»}

To make performance criteria clearer, an assessment grid was designed on the components of the MAPP. Each of the six elements of the MAPP-e.g. situational awareness and management-formed the vertical dimensions of a 6 by 5 grid. For the horizontal dimensions, numbers from 1 to 5 are used to indicate levels of performance from poor (1) to excellent (5). Furthermore, rather then leaving the horizontal grid as a bare, Likert-type scale, 'wordpictures' were developed together with the airline's pilots to describe the performance at each performance level. For example, Figure 2 shows the word pictures for the levels of performance of the category decision-making.

\section{««««" Insert Figure 2 about here »"»»"»»}

The final requirement for the airline was the development of materials that would enable pilots to practice utilizing the assessment grid. Fifteen flight scenarios in the airlines simulator were recorded. These recordings lasted between three and ten minutes and showed varying levels of performance, from poor to excellent. Furthermore, videos depicted various flight regimes, such as taxi, climb, cruise, descent, and landing. There were also various weather scenarios from clear skies to heavy rain at night. These videos constituted the training materials for all pilots within the airline.

\section{Stage 2: Training pilots to assess performance}

The aim of the classroom-based instruction was not to just transfer knowledge to the pilots; this had been already identified as an unsuccessful approach to professional development within the airline (Munro \& Mavin, 2012). The one-day course developed with and for our partner airline initially included 
morning sessions on the MAPP, the new assessment grid, and theory underlying each of the performance components. During the afternoon session, the pilots watched three of the pre-recorded videos.

After a number of training sessions, the authors discussed the structure of the program. Some pilots were having issues with the initial theory, which they struggled incorporating into the videos assessment. Which, in hindsight, was exactly what had been identified from previous years. Subsequently, we inverted the order of the training sessions to emphasize the relationship to practice. By first involving the participating pilots to assess performance using their current perception and preconceived ideas (intuitive judgments) allowed for higher levels of engagement, as theory was not present. As the day evolved, relevant theory was introduced after a common referent had been established with a particular event in the videotaped scenarios. By describing theory later in the session, then using the video as an example made for greater understanding. This simple step considerably improved the uptake of the theory component in the classroom.

Almost all pilots were very positive about the new form of training that the human resources department organized for them. Pilots tended to say that the training 'has given [them] a better understanding of what is being looked for in checks [examination]'. Other examples of positive comments by participants included: 'The video assessments were a standout for me, brilliant! I find video an extremely useful tool for training/ understanding what is required'; 'It has heightened weaknesses for me to work on; Because hearing other people's opinion changed mine several times'; 'Better understanding of what is acceptable and what isn't'; and 'Good to sit back and do analysis of a problem and to understand a better way to manage this situation'. As Table 1 shows, the process of learning about practice by evaluating other pilots' performances was well received by the 92 pilots of the company.

\section{««««" Insert Table 1 about here »»»»»»»}

\section{Stage 3: The real thing ... transferring practice during examination in the simulator}

In our partner airline, all pilots are required to undertake a two-days assessment every six months (known as the two-day bi-annual check). In this assessment, pilots are exposed to varying flight scenarios while in the flight deck (previously known as cockpit) of the simulator, which itself is an identical replica of the real aircraft. During this assessment, our partner airline extends the use of video into the bi-annual check. It implemented video capture into assessment because previous studies had shown that pilots often have difficulties remembering what actually occurred in the simulator (Dismukes, McDonnell, \& Jobe, 2000). Within the simulator itself, a small camera has been mounted strategically to enable video and audio recording of the pilots' performance. The camera has low-light capabilities-for night flying scenarios-and a wide lens to capture all activities that occur in the flight deck. During the debriefing session following an assessment, the flight examiner has the option to playback specific episodes on a wide-screen monitor in the debriefing room, thereby enabling participants to reflect immediately preceding their performance. 
An important improvement on previous video playback system has been the inclusion of the performance criteria from the MAPP (Figure 3). In the course of the examination, the examiner, when identifying an area of interest specific to particular criteria within the MAPP, pushes the button associated with that performance component (i.e., 'situational awareness', 'management', etc.). A mark is left on the video record so that the examiner can rapidly return to that marked scene during the classroom-based debriefing. For example, a flight examiner who has seen that there was 'confusion in checklist usage' has evidence that there was 'a lack of aviation knowledge' and would push the $\mathrm{K}$ button (knowledge). By pressing the 'knowledge' button on the instructor panel in the debriefing room, a list of all 'knowledge' items is listed, so that episode can be rapidly replayed to the pilots. The benefits of this feature are that the examiner can focus pilots on their personal area of need. Furthermore, as pilots are trained to assess performance, analyzing their own performance is not as great a leap as it once was. The use of video now is integrated with our program that emphasizes reflection on/for practice.

\section{««««« Insert Figure 3 about here »"»»»»»}

\section{Reflection as authentic practice: Improving performance and career progression}

In our partner airline, the focus on performance assessment has allowed pilots to take a critical stance with respect to their own performance via the evaluation of the performances of their peers. Reflection on, and for practice, has become integral to the career progress because the assessment tool is integral to training and performance assessment. In the following, we show how the method used:

1. allows pilots to assess performance of others using a current company assessment form and in the process learn to assess performance,

2. allows for the reflection on a pilot's own performance through the lens of the assessment instrument designed with pilots for pilots, and therefore, become better as a pilot,

3. is part of a pilot career trajectory for first officers understanding the practice of captain, and those captains who become flight examiners,

4. better prepares flight examiners to use the assessment tool to reflect on the practice of the pilot during assessment.

Pilots assess performance of others ...

Past research showed that a significant factor in the viability of selfassessment is the development of detailed criteria (Norcini, 2003). This is an important issue that had to be dealt with, as in aviation; the assessment of nontechnical skills was showing high levels of variability when examiners conducted assessment (Brannick, Prince, \& Salas, 2002; Goldsmith \& Johnson, 2002; Holt, Hansberger, \& Boehm-Davis, 2002; O'Connor, Hörmann, Flin, Lodge, \& Goeters, 2002). Inconsistency in assessment appears to occur across all ranks of pilots, including examiners, captains and first officers (Mavin, Roth, \& Dekker, 2013). 
However, a key aim of the assessment process is to improve pilot performance. So, whilst the assessment of technical related problems may be easy to discuss during debriefing, non-technical skills appear to be more problematic.

A considerable problem that was overcome in the early stages of the program was having some level of agreement on what constituted good and poor performance. In the words of one flight examiners 'I can see it, smell it, but I have so much difficulty describing good performance'. By placing criteria in a single list-which is common in aviation, and other profession for that matter-did not alleviate the complexity of what actually constituted good or poor performance. By adopting a policy of a single holistic model (MAPP) signaled to the pilot group the companies view on required performance, permitting pilots of all rank to assess and discuss performance around a common framework. Some pilot's comments after completing the training day include 'You are better able to understand what others think of the standards' and 'Gives a measure of own perspective and confirms the ideal standard'. Additionally, by developing a set of criteria that contained greater detail of each area of technical and non-technical aspects of performance, empowered pilots to discuss performance using a common language. Accordingly, for pilot who (above) had previous difficulty describing performance, it gave him a framework and a common language when discussing performance. For example, in discussing decision-making, the pilot could refer to time, facts and diagnosis, option generation, risk assessment, plan and contingency (Figure 2). By allowing all pilots in the airline to assess performance, using a common framework and language, contributed to all pilots becoming better at assessing performance.

\section{Pilots learn to reflect on their own practice}

Whereas the initial objective was to train pilots on how to assess performance, the end goal was for improvements in self-reflection. Yet, a central issue in the validity of reflective practice is an individual's capacity to recognize issues with his/her own performance level (Dunning \& Suls, 2004). Thus, for example, under-performers tend to have problems self-assessing what they do, with some students over-estimating their performance by as much as five times. High performers, on the other hand, have a tendency to underestimate their performance (Dunning et al., 2003). In this way, individuals 'fail to recognize their own incompetence because that incompetence carries with it a 'double curse' so that 'in many intellectual and social domains, the skills needed to produce correct responses are virtually identical to those needed to evaluate the accuracy of one's responses' (Dunning et al., 2003, p. 85). Because the pilots in our partner airline evaluate the performance of others using a common instrument, a process similar to benchmarking occurs, which aligns the ways in which pilots come to look at performance generally, including their own. They come to view their own practice through the lens of the examiner.

During one session, a training captain had assessed decision-making of the pilots in the video. Subsequently, and after listening to the other pilots, he realized that on reflection, he conducted silent reviews to himself in practice, rather then conducting a review so that it could be heard and understood by the first officer. In this case, the training captain was able to reflect on his own decision-making, and more specifically, in the area of contingency planning 
(Figure 2), which could be improved by 'Voicing your reviewing process'. The aim was to have pilots not only critically assess their performance through benchmarking but also to reflect on their own performance (reflection on action) for future changes in practice (reflection for action). Pilots' comments include: '[A] great way of learning methods to improve your own performance as required' and 'I will use during line training [training during real flight and not simulation] and review my own performance'.

The training focused on improving classroom based instruction. In addition, it was designed to improve the process of post-examination debriefs. Past research showed that pilots, during the debriefing process, do not discuss problematic areas in depth, including the critical areas of non-technical skills. For example, a study of five airlines showed that during debriefing, pilots rarely conducted deep analyses of the preceding practical performance. Furthermore, examiners tended to lead discussions, with some talking more then the other pilots combined (Dismukes et al., 2000). It was concluded that this might have been due to the examiner wanting to maintain a tight control over the debriefing process in the face of alternative approaches. Such approaches include the possibility of allowing pilots to move in a direction that would best allow deep analysis of performance. Nevertheless, an issue that was not considered, and is posited, is that the pilots may have not have had the necessary skills or understanding to actually conduct a deep analysis of their own performance. One pilot wrote, that the training day in the classroom 'served as a reminder of how difficult the examiners job can be'. It is now suggested that with this type of training, the examiners and company pilots will be better skilled to conduct a deeper analysis of performance.

\section{The training is part of a pilot's career trajectory}

In our partner airline, assessing performance has now become an integral part of the career trajectory. When a pilot first joins the company, new first officers spend time reviewing and assessing practice. Even before the pilots are actually fully qualified to fly in the airline, they are becoming familiar with performance expectations. In the early parts of the pilots' career with the airline, they come to understand the components of piloting performance-both the first officer and captain performance-that trainers and examiners are seeking, because they themselves look at the performance of others through the same lens. By doing assessments, even the first officer comes to look at performance through the lens of an examiner, and, therefore, develop intimate familiarity with both sides of the process. They learn to reflect on their own practice by selfassessing different performance components. The debriefing process following the examination plays an integral and critical part in learning. For one first officer, better understanding performance 'Has given [him] a better understanding of what is being looked for in checks [examinations]'.

When captains become trainers of new pilots, they use the same assessment form in making decisions that affect the careers of others. Some of the training captains eventually become flight examiners and it is here that we now arrive, finally, at a juncture where the outlined method has been used previously in practice. When training captains are promoted to the position of examiner, they learn the process of assessing performance. However, in the current approach, 
the aim of our partner airline is that this will no longer occur, as performance assessment is now integral across all ranks of pilots.

Flight examiners are better equipped to use the assessment tool to reflect on the practice of pilot assessment

By completing the loop of this new method of training, a clear marriage has occurred between an airline and the research team. One of the key benefits that have arisen from closely aligning research and practice concerns the feedback on practice. In a recent workshop with senior examiners, findings from a research project within the airline where delivered. In a seminar-style approach, the findings where presented to the examiners. The presentation gave rise to a lot of in-depth discussion and reflection. One of the findings presented had identified that differences existed between how examiners, captains, and first officers view performance (e.g., Mavin et al., 2013). The results suggested that the examiners rated to performances lower then captains, and captains rated performances lower then first officers. During a discussion on the implication to practice, examiners personalized it with previous examples they had experienced. Some outlined difficulties they had experienced getting captains and first officers to agree with final assessments (reflection on action). Whereas the research team was able to facilitate new approaches to debriefing that could assist in bridging these current differences (reflection for action), the final goal is that some form of training will possibly close this gap. The envisioned approach includes benchmarking, where pilots would view videos together and discuss their ratings until agreements are achieved.

\section{Coda}

The year of this writing marked the 30th anniversary of The Reflective Practitioner (Schön, 1983). As a consequence of the discussion and critique the work has engendered, the reflective practice approaches have improved. Yet there is still only limited literature on its underlying principles and theories (Thompson \& Pascal, 2012). These authors argue that much of the practice and insightful writing in the field detail reflection, rather then, further developing theory of its use; the argument being that reflective practice as a method of profesional development, appears to have moved ahead of the foundational theory. The purpose of this paper is to contribute to the literature by presenting and theorizing a model in which reflection on/for practice becomes an integral component of a career. We use an example from aviation to show how reflective practice is encouraged and aligned when practitioners assess the performance of their peers by means of an assessment form (instrument) that is also used to assess their own performance. This approach appears to us to give an increased relevance to reflective practice, because it no longer is an add on but an integral feature of a profession and the career progress within it.

It is suggested that developing a clear, theoretical understanding of what constitutes acceptable perfomance is the first step in developing reflective practice. By designing criteria that improves the ability to cleary articulate perfomance through a common language, is the second. Finally, broadening 
performance assessment training to all might be a way of improving an individual's ability to reflect on their own practice and that of others.

The question might be posed whether the model is transportable to other professions. Whereas we cannot respond for all professions, in our own work as teachers, this has already been part of the improvement of an entire science department (Tobin \& Roth, 2006). These authors report that as part of professional development, all teachers in the department, including the department head, (a) observed lessons of other teachers, (b) cotaught a number of lessons per year with other teachers, (c) evaluated other teachers, and (d) evaluated their own performances through reflection on/for practice with supporting evidence from videotaped lessons. Observing other teachers and working at their elbow allowed each individual to become aware of his/her own practices of teaching sciences, especially while observing themselves in the videotapes. Within a three-year period, all science teachers at the school had improved their teaching as indicated in their self-reports and in the reports of outside observers. We envision the possibility that other forms of practice could include cycles of reflection on/for practice with the practice and career progress.

The experience with our partner airline has been very positive. However, despite making reflection on and for practice integral to the provision, problems remain. Thus, whereas the airline attempted to improve the inter-examiner reliability during the assessment process, our ongoing research shows a high degree of variability in what assessing pilots see in the videos and how different types of events are weighted as part of their overall performance assessment, which always has to lead to a pass/fail decision (Roth \& Mavin, 2013). Using a modified think-aloud protocol, we found that the same segment-an instant where the flying pilot asked whether the standard operating procedure called for a right turn-was used as evidence for failing the pilot because he had lost situational awareness or for supporting 'good communication' because the pilot, who was also the captain (more senior, power-over situation) confirmed the next action rather than engaging in the wrong process (Roth \& Mavin, in press). Our future work with the airline will have to work out the precise role of the assessment model and the associated assessment instrument during training. One hypothesis is that it allows pilots to become aware of different performance components and, thereby, of their practice as a whole. On the other hand, it may turn out not to be a consistent measurement tool, which would require further modifications so that it could serve its function as organizing a pilots' career.

\section{References}

Betts, J. (2004). Theology, therapy or picket line? What's the good of reflective practice in management education? Reflective Practice, 5, 239-251.

Billett, S. (2010). Learning through practice. In S. Billett (Ed.), Learning through practice: Models, traditions, orientations and approaches (pp. 1-13). Dordrecht, The Netherlands: Springer.

Brannick, M. T., Prince, C., \& Salas, E. (2002). The reliability of instructor evaluations of crew performance: Good news and not so good news. The International Journal of Aviation Psychology, 12, 241-261. 
Brett-MacLean, P. J., Cave, M.-T., Yiu, V., Kelner, D., \& Ross, D. J. (2010). Film as a means to introduce narrative reflective practice in medicine and dentistry: a beginning story presented Reflective Practice: International and Multidisciplinary Perspectives, 11, 499-516.

Clouder, L. (2000). Reflective practice: Realising its potential. Physiotheropy, 86, 517-522.

Dismukes, K., McDonnell, L. K., \& Jobe, K. K. (2000). Facilitating LOFT debriefings: Instructor techniques and crew participation. The International Journal of Aviation Psychology, 10, 35-57.

Dochy, F., Segers, M., \& Sluijsmans, D. (1999). The use of self-, peer and coassessment in higher education: a review. Studies in Higher Education, 24, 331-350.

Dunning, D., Johnson, K., Ehrlinger, J., \& Kruger, J. (2003). Why people fail to recognize their own incompetence. Current Directions in Psychological Science, 12, 83-87.

Dunning, D., \& Suls, J. M. (2004). Flawed self-assessment implications for health, education, and the workplace. Psychological Sciene in the Public Interest, 5 (3), 69-106.

Emad, G., \& Roth, W.-M. (2008). Contradictions in practices of training for and assessment of competency: a case study from the maritime domain. Education + Training, 50, 260-272.

Eraut, M. (2010). Knowledge, working practices, and learning. In S. Billett (Ed.), Learning through practice: Models, traditions, orietations and approaches (pp. 37-58). Dordrecht, The Netherlands: Springer.

Flin, R., O'Connor, P., \& Crichton, M. (2009). Safety at the sharp end. Aldershot, UK: Ashgate.

Goldsmith, T. E., \& Johnson, P. J. (2002). Assessing and improving evaluation of aircrew performance. The International Journal of Aviation Psychology, 12, 223-240.

Gurung, R. A. R., Daniel, D. B., \& Landrum, R. E. (2012). A multisite study of learning in introductory psychology courses. Teaching of Psychology, 39, 170175.

Helmreich, R. L., \& Foushee, H. C. (1993). Why crew resource management? Empirical and theoretical bases of human factors in aviation. In E. L. Weiner, B. G. Kanki, \& R. L. Helmreich (Eds.), Cockpit resource management (pp. 3-46). San Diego, CA: Academic Press.

Holden, R., \& Griggs, V. (2011). Not more learning logs! A research based perspective on teaching reflective learning within HR professional education. Human Resource Development International, 14, 483-491.

Holt, R. W., Hansberger, J. T., \& Boehm-Davis, D. A. (2002). Improving rater calibration in aviation: A case study. The International Journal of Aviation Psychology, 12, 305-330.

Howarth, A. (2005). Using reflection in complementary therapies: Critical reflection and pain management. In C. Johns \& D. Freshwater (Eds.), Transforming nursing through reflective practice (pp. 129-141). Oxford, UK: Blackwell.

Hulsman, R. L., Harmsen, A. B., \& Fabriek, M. (2009). Reflective teaching of medical communication skills with DiViDU: Assessing the level of student 
reflection on recorded consultations with simulated patients. Patient Education and Counseling, 74, 142-149.

Johns, C. (1995). The valuse of reflective practice for nursing. Journal of Clinical Nursing, 4, 23-30.

Johnston, A. N., Rushby, N., \& Maclean, I. (2000). An assistant for crew performance assessment. The International Journal of Aviation Psychology, 10, 99-108.

Kelly, G., Luke, A., \& Green, J. (2008). What counts as knowledge in educational settings: Disciplinary knowledge, assessment and curriculum. Review of Research in Education, 32, vii-x.

Koole, S., Dornan, T., Aper, L., De Wever, B., Scherpbier, A., Valcke, M., . . . Derese, A. (2012). Using video-cases to assess student reflection: Development and validation of an instrument. BMC Medical Education, 12(1), 22-29.

Lane, J. L., \& Gottlieb, R. P. (2004). Improving the interviewing and selfassessment skills of medical students: Is it time to readopt videotaping as an educational tool? Ambulatory Pediatrics, 4, 244-248.

Lister, P. G., \& Crisp, B. R. (2007). Critical incident analyses: A practice learning tool for students and practitioners. Practice: Social Work in Action, 19, 47-60.

Mann, K. V. (2010). Self-assessment: The complex process of determining 'How we are doing'-A perspective from medical education. Academy of Management Learning \& Education, 9, 305-313.

Mavin, T. J., \& Dall'Alba, G. (2010, April). A model for integrating technical skills and NTS in assessing pilots' performance. Paper presented at the 9th International Symposium of the Australian Aviation Psychology Association, Sydney, Australia.

Mavin, T. J., \& Murray, P. (2010). The development of airline pilot skills through practice. In S. Billett (Ed.), Learning through practice: Models, traditions, orientations and approaches (pp. 268-286). Dordrecht, The Netherlands: Springer.

Mavin, T. J., Roth, W.-M., \& Dekker, S. W. A. (2013). Understanding variance in pilot performance ratings: Two studies of flight examiners, captains and first officers assessing the performance of peers. Aviation Psychology and Applied Human Factors, 3, 53-62.

Munro, I., \& Mavin, T. J. (2012). Crawl-walk-run. Paper presented at the 10th International Symposium of the Australian Aviation Psychology Association. Sydney, Australia.

Norcini, J. (2003). Peer assessment of competence. Medical Education, 37, 539543.

O'Connor, P., Hörmann, H. J., Flin, R., Lodge, M., \& Goeters, K.-M. (2002). Developing a method for evaluating crew resource management skills: A European perspective. The International Journal of Aviation Psychology, 12, 263-285.

O'Connell, T. S., \& Dyment, J. E. (2011). The case of reflective journals: Is the jury still out? Reflective Practice: International and Multidisciplinary Perspectives, $12,47-59$.

Richards, P., Collins, D., \& Mascarenhas, D. R. D. (2012). Developing rapid highpressure team decision-making skills. The integration of slow deliberate reflective learning within the competitive performance environment: A case 
study of elite netball. Reflective Practice: International and Multidisciplinary Perspectives, 13, 407-424.

Roth, W.-M. (2010). Learning in praxis, learning for praxis. In S. Billett (Ed.), Learning through practice: models, traditions, orientations (pp. 21-36) Dordrecht, The Netherlands: Springer.

Roth, W.-M., \& Marvin, T. J. (2013). Assessment of non-technical skills: From measurement to categorization modeled by fuzzy logic. Aviation Psychology and Applied Human Factors, 3, 73-82.

Roth, W.-M., \& Mavin, T. J. (in press). Peer assessment of aviation performance: Inconsistent for good reasons. Cognitive Science.

Rowperfect. (2014). Video analysis: A guide for rowers and coaches. Retrieved from http://rowperfect.co.uk/video-analysis-a-guide-for-rowers-coaches/

Scherer, L. A., Chang, M. C., Meredith, J. W., \& Battistella, F. D. (2003). Videotape review leads to rapid and sustained learning. American Journal of Surgery, $185,516-520$.

Schön, D. A. (1983). The reflective practitioner. New York, NY: Basic Books.

Schön, D. A. (1987). Educating the reflective practioner. San Francisco, CA: JosseyBass.

Sitzmann, T., Ely, K., Brown, K. G., \& Bauer, K. N. (2010). Self-assessment of knowledge: A cognitive learning or affective measure? Academy of Management Learning \& Education, 9, 169-191.

Thompson, N., \& Pascal, J. (2012). Developing critically reflective practice. Reflective Practice: International and Multidisciplinary Perspectives, 13, 311325.

Tobin, K., \& Roth, W.-M. (2006). Teaching to learn: A view from the field. Rotterdam, The Netherlands: Sense Publishers.

Todd, G. (2005). Reflective practice and socratic dialogue. In C. Johns \& D. Freshwater (Eds.), Transforming nursing through reflective practice (pp. 3854). Oxford, UK: Blackwell.

Ward, M., MacRae, H., Schlachta, C., Mamazz, J., Poulin, E., Reznick, R., \& Regehr, G. (2003). Residentself-assessmentofoperativeperformance. American Journal of Surgery, 185, 521-524.

\section{Captions}

Figure 1 Model for Assessing a Pilot Performance

Figure 2. Criteria defined for decision-making. Word pictures developed for five levels of performance from below standard (1) to excellent (5).

Figure 3. a. Pilots (left image) seated in the simulator during performance assessment. The instructors seat and instructor panel (two touch screens) can be seen in the bottom left. b. An expanded view of the quick action buttons the instructor can push. Note the Event Mark on the bottom of the screen enable the instructor to identify performance issues for later discussion in the debriefing (Note: $\mathrm{S}=$ situational awareness, $\mathrm{D}=$ decisional making, $\mathrm{F}=$ =aircraft within parameters, $\mathrm{K}=$ knowledge, $\mathrm{M}=$ management and $\mathrm{C}=$ communication). 
Table 1. Survey of responses for use of video assessment

\begin{tabular}{lccc}
\hline \multicolumn{1}{c}{ Question } & Mean & SD \\
\hline $\begin{array}{l}\text { I enjoyed the overall approach to using video scenarios during ground based } \\
\text { instruction }\end{array}$ & 5.15 & .99 \\
$\begin{array}{l}\text { 2. I enjoyed the collaborative process involved in discussing the performance of } \\
\text { other pilot's performance in the video scenarios }\end{array}$ & 5.00 & .96 \\
$\begin{array}{l}\text { 3. Applying the assessment standards to other pilot's performance in the video } \\
\text { scenarios improved my learning }\end{array}$ & 4.83 & 1.00 \\
$\begin{array}{l}\text { 4. Applying the assessment standards to other pilot's performance in the video } \\
\text { scenarios improved my learning }\end{array}$ & 4.83 & 1.00 \\
$\begin{array}{l}\text { 5. The collaborative process involved in discussing the pilot's performance in the } \\
\text { video scenarios improved my learning }\end{array}$ & 4.81 & & .95 \\
$\begin{array}{l}\text { 6. Having to personally apply the assessment standards to the pilot's performance } \\
\text { in the video scenario has caused me to think about my own practice }\end{array}$ & 5.01 & & .94 \\
$\begin{array}{l}\text { 7. The collaborative approach to discussing assessment standards relevant to the } \\
\text { pilot's performance in the video scenarios has caused me to think about my own } \\
\text { practice }\end{array}$ & 4.80 & & .94 \\
$\begin{array}{l}\text { 8. Using video scenarios has caused me to develop enhanced action plans for my } \\
\text { own future practice }\end{array}$ & 4.73 & 1.06 \\
\hline
\end{tabular}

Rating scale: Scale 1 (highly disagree) - 6 


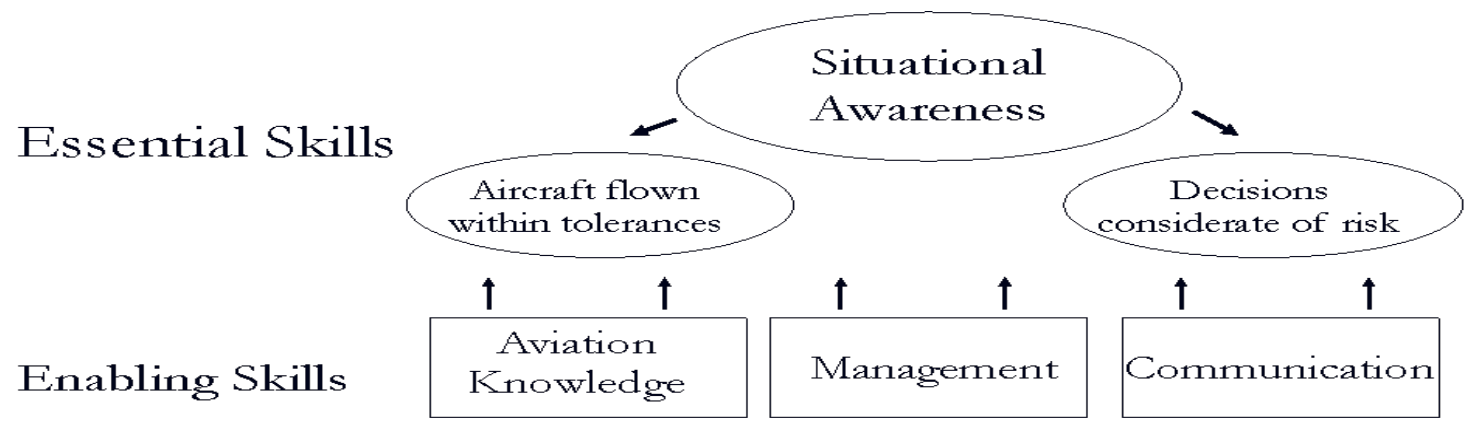

Figure 1 


\begin{tabular}{|c|c|c|c|c|c|}
\hline $\begin{array}{l}\text { Decision } \\
\text { making }\end{array}$ & 1 & 2 & 3 & 4 & 5 \\
\hline Time & $\begin{array}{l}\text { Poor grasp of time } \\
\text { available. }\end{array}$ & $\begin{array}{l}\text { - Limited time } \\
\text { appreciation, led to } \\
\text { rushed or delayed } \\
\text { decision. }\end{array}$ & $\begin{array}{l}\text { Decision made in time } \\
\text { available. }\end{array}$ & $\begin{array}{l}\text { Decision made within } \\
\text { clearly established time } \\
\text { constraints. }\end{array}$ & $\begin{array}{l}\text { - Consistently identified } \\
\text { problem, choosing best } \\
\text { possible option in time } \\
\text { available, appearing } \\
\text { almost intuitive. }\end{array}$ \\
\hline $\begin{array}{l}\text { Facts and } \\
\text { Diagnosis }\end{array}$ & $\begin{array}{l}\text { - Facts not considered, } \\
\text { leading to ill-informed or } \\
\text { wrong identification or } \\
\text { diagnosis. }\end{array}$ & $\begin{array}{l}\text { - Correct diagnosis, } \\
\text { though some facts not } \\
\text { considered creating } \\
\text { initial difficulty. }\end{array}$ & $\begin{array}{l}\bullet \text { Most facts taken into } \\
\text { account and problem } \\
\text { correctly identified or } \\
\text { diagnosed. }\end{array}$ & $\begin{array}{l}\text { - All facts taken into } \\
\text { account; problem } \\
\text { correctly identified or } \\
\text { diagnosed. }\end{array}$ & $\bullet$ \\
\hline $\begin{array}{l}\text { Option } \\
\text { generation }\end{array}$ & $\begin{array}{l}\text { - Inadequate range of } \\
\text { options considered. }\end{array}$ & - Limited range of options. & $\begin{array}{l}\text { - Obvious options } \\
\text { considered. }\end{array}$ & $\begin{array}{l}\text { - All suitable options } \\
\text { considered. }\end{array}$ & $\bullet$ \\
\hline $\begin{array}{l}\text { Risk } \\
\text { assessment }\end{array}$ & $\begin{array}{l}\text { - Inappropriate risk } \\
\text { assessment. }\end{array}$ & - Some risks assessed. & $\begin{array}{l}\text { - Most risks taken into } \\
\text { account. }\end{array}$ & - Sound risk assessment. & $\begin{array}{l}\text { - Thorough risk } \\
\text { assessment. }\end{array}$ \\
\hline $\begin{array}{l}\text { Plan }+ \\
\text { contingency }\end{array}$ & - Unable to develop plan. & $\begin{array}{l}\text { - Difficulty developing a } \\
\text { plan. } \\
\text { - Limited contingency } \\
\text { planning. }\end{array}$ & $\begin{array}{l}\text { - Developed a plan. } \\
\text { - Adequate contingency } \\
\text { planning. }\end{array}$ & $\begin{array}{l}\text { - Developed a sound plan. } \\
\text { - Sound contingency } \\
\text { planning. }\end{array}$ & $\begin{array}{l}\text { - Detailed contingency } \\
\text { planning. } \\
\text { - Clearly outlined the plan, } \\
\text { with no doubt to } \\
\text { intentions from any crew } \\
\text { member. }\end{array}$ \\
\hline
\end{tabular}

Figure 2 


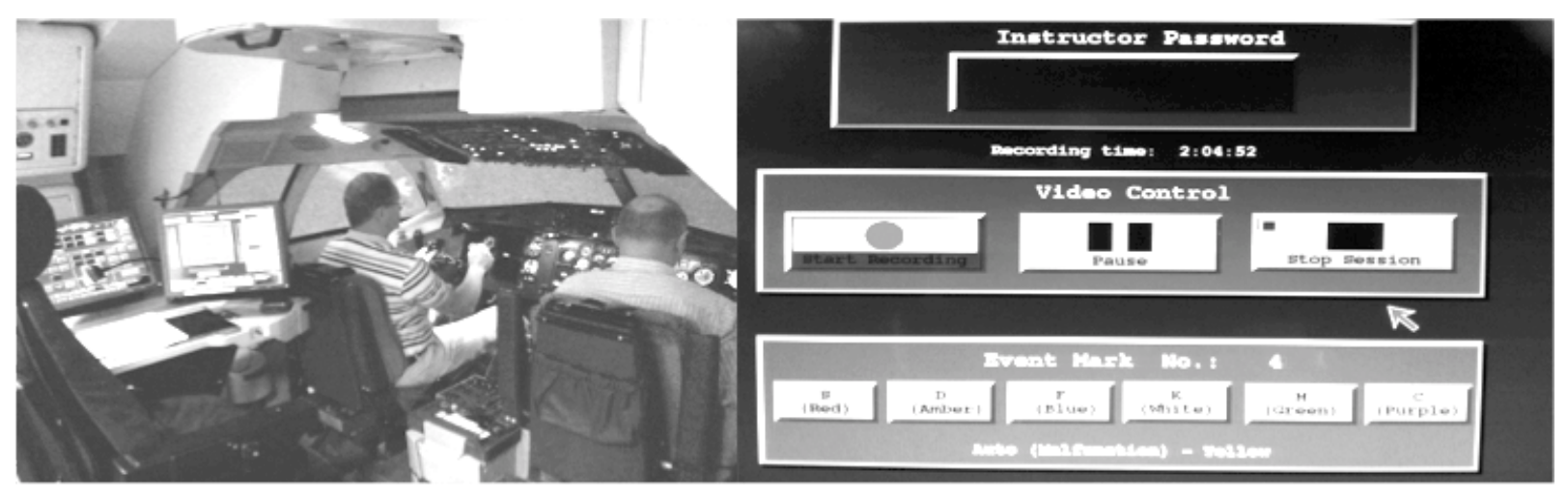

Figure 3 